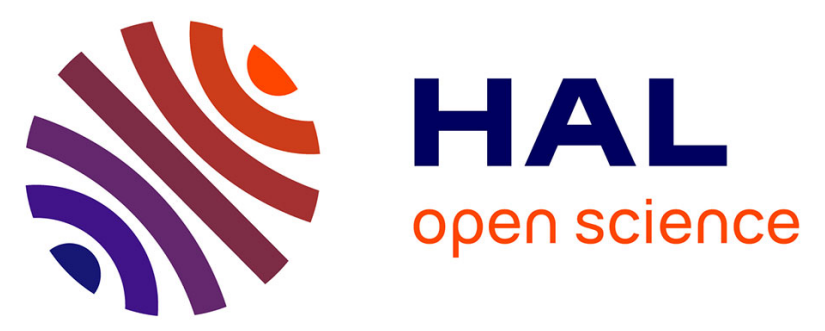

\title{
Optimization of Anticorrosive Zinc Coatings: Tuning the Adhesion of Zinc/Silica Contact by Interfacial Ternary Oxide Formation
}

\author{
Jacopo Baima, Jacek Goniakowski, Claudine Noguera, Alexey Koltsov, \\ Jean-Michel Mataigne
}

\section{To cite this version:}

Jacopo Baima, Jacek Goniakowski, Claudine Noguera, Alexey Koltsov, Jean-Michel Mataigne. Optimization of Anticorrosive Zinc Coatings: Tuning the Adhesion of Zinc/Silica Contact by Interfacial Ternary Oxide Formation. Journal of Physical Chemistry C, 2020, 124 (17), pp.9337-9344. 10.1021/acs.jpcc.0c00617 . hal-02875316

\section{HAL Id: hal-02875316 https://hal.science/hal-02875316}

Submitted on 19 Jun 2020

HAL is a multi-disciplinary open access archive for the deposit and dissemination of scientific research documents, whether they are published or not. The documents may come from teaching and research institutions in France or abroad, or from public or private research centers.
L'archive ouverte pluridisciplinaire HAL, est destinée au dépôt et à la diffusion de documents scientifiques de niveau recherche, publiés ou non, émanant des établissements d'enseignement et de recherche français ou étrangers, des laboratoires publics ou privés. 


\title{
Optimization of Anticorrosive Zinc Coatings: Tuning the Adhesion of Zinc/Silica Contact by Interfacial Ternary Oxide Formation
}

\author{
Jacopo Baima, ${ }^{\dagger} \uparrow$ Jacek Goniakowski, ${ }^{* \dagger}$ Claudine Noguera, ${ }^{\dagger}$ Alexey Koltsov, \\ and Jean-Michel Mataigne \\ †CNRS and Sorbonne Université, UMR 7588, Institut des Nanosciences de Paris (INSP) 4 \\ place Jussieu, 75005 Paris, France \\ $\ddagger$ ArcelorMittal Maizières Research, voie Romaine, F-57280, Maizières lès Metz, France. \\ \ArcelorMittal Maizières Research, voie Romaine, F-57280, Maizières lès Metz, France.
}

E-mail: jacek.goniakowski@insp.jussieu.fr

\begin{abstract}
Formation of mixed compounds at interfaces between materials often has significant impact on the properties of the junction. With the goal of assessing if interfacial oxide mixing improves the adhesion of anti-corrosive zinc coatings on silica, we report an ab initio study of the structural, electronic, and adhesion characteristics of interfaces between zinc and zinc silicate. We show that, regardless the precise thermodynamic conditions, ZnO-rich zinc silicate interfaces are more stable than $\mathrm{SiO}_{2}$-rich ones because their formation does not require breaking strong $\mathrm{Si}-\mathrm{O}$ bonds. Moreover, we find that zinc adhesion at such $\mathrm{ZnO}$-rich interfaces is by at least a factor two larger than that of the zinc/silica contact. Due to a dense network of interfacial Zn-O bonds, this improvement does not produce any unfavorable decohesion effects in the zinc deposit. The formation of an interfacial silicate layer enables the suppression of the weak zinc/silica interface, which is responsible for the poor zinc adhesion. The cohesive cleavage within zinc predicted for the complex zinc/silicate/silica junction offers a promising improvement of performances of anti-corrosive zinc coatings of Si-rich steel grades, of crucial importance in steel-making and automotive industries.
\end{abstract}

\section{Introduction}

Metal/oxide interfaces have been intensively studied because of their intrinsic scientific importance, and their applications that range from microelectronics, to engineering of thermal coatings, or formation of protective scales. However, with the continuously growing complexity of materials used by modern industries, new questions and challenges arise. For example, the improvement of adhesion between large gap oxides (such as silica or alumina) and late transition metals (such as zinc) ap- pears nowadays as a key challenge for the optimization of anti-corrosive zinc coatings of modern steel grades, of crucial importance in steel-making and automotive industries. Routinely, before applying the zinc coating, coldrolled steel strips undergo a recrystallisation annealing to remove stresses and residual iron oxides $^{1,2}$. Since the novel, advanced high strength steels (AHSS) are purposely enriched in strengthening elements, such as $\mathrm{Al}, \mathrm{Si}$ and $\mathrm{Mn}^{3-9}$, the annealing results in a selective oxidation of the electropositive alloyed elements. Segregation of the corresponding oxides at the 
steel surface reduces dramatically the adhesion of the anti-corrosive zinc protection ${ }^{2,5}$.

We have recently shown that the most stable, stoichiometric silica terminations do indeed interact very weakly with zinc due to a reconstruction of silica surface into siloxane rings. ${ }^{10}$ While breaking these surface groups enables the formation of stronger interfacial Zn-O bonds, the process has a large activation energy and is thus expected not to spontaneously occur. In this context surface pre-hydroxylation was proposed as a promising route towards breaking surface siloxanes and improving the interface adhesion. ${ }^{11}$ However, such procedure has the drawback of reducing the cohesion of the zinc deposit.

An alternative route may rely on the formation of a mixed interfacial oxide phase, such as zinc silicate $\left(\mathrm{Zn}_{2} \mathrm{SiO}_{4}\right)^{12-15}$ which, depending on the thermodynamical conditions, could assure good adhesion characteristics of the $\mathrm{Zn} / \mathrm{Zn}_{2} \mathrm{SiO}_{4} / \mathrm{SiO}_{2}$ heterostructure. Indeed, mixing two oxides has long been considered as a promising way to engineer their properties and the formation of a mixed interfacial compound is thus expected to have a significant impact on the junction strength. In the present case, low density of silicon atoms at silicate surfaces will indeed prevent the formation of siloxane rings, ${ }^{15}$ thus providing mono-coordinated surface oxygen atoms apt to form strong interfacial $\mathrm{Zn}-\mathrm{O}$ bonds. Moreover, the existing network of $\mathrm{Zn}-\mathrm{O}$ bonds within the silicate may naturally propagate towards the zinc deposit, further improving the adhesion.

In this context, the main goal of the present study is a theoretical assessment of the structure and energetics of $\mathrm{Zn} / \mathrm{Zn}_{2} \mathrm{SiO}_{4}$ interfaces under a wide range of thermodynamic conditions, as well as a comparison of their adhesion characteristics to those of the weak $\mathrm{Zn} / \mathrm{SiO}_{2}$ contact. Based on a series of numerical calculations, we predict a significant adhesion improvement, able to change the character of cleavage from interfacial to cohesive. We rationalize it by the enhanced thermodynamic stability of $\mathrm{ZnO}$-rich interfaces, characterized by a dense network of Zn-O bonds. More importantly, we explicitly show that our predictions remain valid also in the limit of ultra-thin interfacial silicate films between zinc and silica, which are likely more relevant for practical realizations.

The paper is organized as follows. After presenting the details and settings of the computational approach in Sec. 2, in Sec. 3 we describe the structural and electronic properties of zinc/silicate interface configurations of different stoichiometry, analyze their thermodynamic stability as a function of oxygen conditions, and discuss the interface strength as estimated by the separation energies. Section 4 is devoted to a comparative analysis of the zinc/silicate and zinc/silica interfaces, to a discussion of the contact between silicate and silica, and to an assessment of the validity of our predictions in the limit of ultra-thin silicate film, before the conclusion.

\section{Computational methods and settings}

All calculations were performed within the Density Functional Theory (DFT) implemented in VASP (Vienna ab initio simulation package). ${ }^{16,17}$ We have used a dispersion-corrected GGA exchange-correlation functional (optB86$\mathrm{vdW}),{ }^{18-20}$ as it is known to improve the description of adhesion characteristics at weakly interacting metal/oxide interfaces with respect to standard GGAs. In particular dispersive interactions account for the majority of the adhesion energy between zinc and reconstructed silica surfaces. ${ }^{10}$ In Tab. 1 we show that also the cohesive and surface energies of zinc, zinc oxide, and silica are somewhat improved by inclusion of van der Waals interactions. The interaction of valence electrons with ionic cores is described within the projector augmented wave (PAW) method. ${ }^{21,22}$ The Kohn-Sham orbitals are developed on a plane-wave basis set with a cutoff energy of $400 \mathrm{eV}$, and we use a $\Gamma$ centered $6 \times 6$ Monkhorst-Pack grid. The selfconsistent iterative solution of the electronic Hamiltonian is pursued until energy differences become less than $10^{-6} \mathrm{eV}$. Atomic charges are estimated with the partition scheme proposed 
Table 1: Comparison between bulk formation energy $\mathbf{E}_{f}$ (eV/f.u.) and surface energy $\mathbf{E}_{\text {surf }}\left(\mathbf{J m}^{-2}\right)$ of $\beta$ cristobalite silica, zinc, and zinc oxide obtained with standard GGA PW91 ${ }^{26}$ and vdW-corrected functional optB86-vdw. The surface orientations are $\mathrm{SiO}_{2}(001)$, $\mathrm{Zn(0001)}$ and $\mathrm{ZnO}(10 \overline{1} 0)$.

\begin{tabular}{lccccc} 
& \multicolumn{2}{c}{$\mathrm{E}_{f}$} & \multicolumn{2}{c}{$\mathrm{E}_{\text {surf }}$} \\
& GGA & vdW & exp. $^{27}$ & GGA & vdW \\
\hline $\mathrm{SiO}_{2}$ & 4.31 & 4.40 & 4.72 & 2.02 & 2.28 \\
$\mathrm{Zn}$ & 1.12 & 1.27 & 1.35 & 0.31 & 0.52 \\
$\mathrm{ZnO}$ & 3.03 & 3.19 & 3.63 & 0.87 & 1.12
\end{tabular}

by Bader, ${ }^{23,24}$ and atomic configurations are plotted with VESTA. ${ }^{25}$

Since several zinc silicate polymorphs have been reported to form in thin films and at $\mathrm{Si} / \mathrm{ZnO}$ or $\mathrm{SiO}_{x} / \mathrm{ZnO}$ interfaces ${ }^{12-14}$, following our previous study, ${ }^{15}$ we have focused on the tetragonal $\mathrm{t}-\mathrm{Zn}_{2} \mathrm{SiO}_{4}$ phase, characterized by a relatively small unit cell. Its local structure is remarkably similar to that of the most stable rombohedral willemite phase ${ }^{28,29}$. $\mathrm{t}-\mathrm{Zn}_{2} \mathrm{SiO}_{4}$ prevails at a pressure of about $25 \mathrm{kbar}$, is only slightly less stable than willemite at ambient pressure, ${ }^{14}$ and has been found at various interfaces. ${ }^{12,14}$

Surface calculations Surface calculations are performed as detailed in our previous work, ${ }^{15}$ and summarized in the following. Nine alternative surface terminations of different stoichiometry and polar character preserve the $(1 \times 1)$ $\mathrm{Zn}_{2} \mathrm{SiO}_{4}(001)$ surface periodicity. ${ }^{15}$ Their relative stability depends on the values of the oxygen, zinc, and silicon chemical potentials $\mu_{\mathrm{O}}$, $\mu_{\mathrm{Zn}}$ and $\mu_{\mathrm{Si}}$. Since surface terminations are in equilibrium with the underlying bulk silicate, these chemical potentials are related through:

$$
g_{\mathrm{Zn}_{2} \mathrm{SiO}_{4}}^{\text {bulk }}=2 \mu_{\mathrm{Zn}}+4 \mu_{\mathrm{O}}+\mu_{\mathrm{Si}}
$$

where $g_{\mathrm{Zn}_{2} \mathrm{SiO}_{4}}^{\text {bulk }}=G_{\mathrm{Zn}_{2} \mathrm{SiO}_{4}}^{\text {bulk }} / N$ is the Gibbs free energy per formula unit, which implicitly depends on temperature and pressure. As we are interested in interfaces with metallic zinc, the zinc chemical potential is fixed to its bulk value, $\mu_{\mathrm{Zn}}=g_{\mathrm{Zn}}^{\text {bulk }}$. As a consequence, surface energies can be expressed as a function of a single chemical potential only. We choose $\mu_{\mathrm{O}}$ (as it is the most experimentally accessible) and we refer it to the total energy of a free oxygen molecule, $\Delta \mu_{\mathrm{O}}=\mu_{\mathrm{O}}-\frac{1}{2} E_{\mathrm{O}_{2}}$. Following standard procedures of $a b$ initio thermodynamics, we approximate bulk free energy differences with the difference between the respective total energies at $0 \mathrm{~K}$.

To compute surface and interface energies, we use silicate slabs with at least 9 atomic layers. As to limit the propagation of structural distortions inside the slabs and to improve the convergence with respect to their thickness, we use asymmetric slabs with one bare termination (labeled $B$ in the following) and one fully hydroxylated termination ( $A$ in the following). The latter is chosen as the non-polar $\mathrm{SiO}_{2}$-rich termination, described in Sec. 3 and in Ref. 15, with 3 dissociated water molecules per surface unit cell. The sum of the two surface energies is then obtained as:

$$
\begin{array}{r}
\sigma_{\mathrm{B}}\left(\mu_{\mathrm{O}}\right)+\sigma_{A}\left(\mu_{\mathrm{O}}\right)=\left(E_{\mathrm{Zn}_{2} \mathrm{SiO}_{4}}^{a-s a b}-E_{\mathrm{Zn}_{2} \mathrm{SiO}_{4}}^{\text {bulk }}\right. \\
\left.-\Delta N_{\mathrm{Zn}} E_{\mathrm{Zn}}^{b u l k}-\Delta N_{\mathrm{O}}\left(\frac{1}{2} E_{\mathrm{O}_{2}}^{\text {gas }}+\Delta \mu_{\mathrm{O}}\right)-3 E_{\mathrm{H}_{2} \mathrm{O}}\right) / S
\end{array}
$$

where $E_{\mathrm{Zn}_{2} \mathrm{SiO}_{4}}^{a-s l a b}$ is the energy of the asymmetric slab, $\Delta N_{\mathrm{i}}$ is the number of excess atoms of specie $\mathrm{i}$ with respect to the $\mathrm{Zn}_{2} \mathrm{SiO}_{4}$ stoichiometry, and $E_{\mathrm{H}_{2} \mathrm{O}}$ is the total energy of a water molecule. Since the evaluation of $\sigma_{\mathrm{B}}$ requires the knowledge of $\sigma_{\mathrm{A}}$, the total energy of a symmetric slab with both terminations equivalently hydroxylated with 3 water molecules each was also calculated.

Interface calculations The simulations of $\mathrm{Zn} / \mathrm{Zn}_{2} \mathrm{SiO}_{4}$ interfaces make use of the same asymmetric $\mathrm{Zn}_{2} \mathrm{SiO}_{4}$ slabs with 6-layer-thick zinc (0001) films deposited on their bare terminations. In order to reduce mismatch effects, we have used $(2 \times 1)-\operatorname{Zn}(0001) \|(1 \times 1)$ $\mathrm{Zn}_{2} \mathrm{SiO}_{4}(001)$ coincidence cells. The resulting interface mismatch along the two in-plane directions is less than $3 \%$, with an angle mismatch of $9 \%$. As to further reduce the interfacial strain we fix in all cases the lattice parameters and angles to the average values between the zinc and the silicate ones. We have verified that, despite 
this distortion, the zinc deposits preserve their hexagonal lattice and the (0001) orientation. Since the distortion modifies zinc and silicate surface energies by less than 0.08 and $0.25 \mathrm{~J}$ $\mathrm{m}^{-2}$, respectively, the overall systematic bias induced by the interface strain is of the order of $0.3 \mathrm{~J} \mathrm{~m}^{-2}$.

In order to determine the most stable interface configurations for each stoichiometry, two series of independent optimizations were performed with reduced accuracy, starting from various interface registries between the two lattices. The first screening consists of two steps: the structural optimization of interfaces with 100 different registries, and the further relaxation of the 20 lowest energy structures at an intermediate accuracy. The most stable structures among these latter ones are then converged at full accuracy. Both screening steps are performed using soft oxygen pseudopotentials, a plane-wave cutoff of $280 \mathrm{eV}$, and a $2 \times 2$ $\mathrm{k}$-point grid. For the first step we used the low precision setting of VASP and an energy threshold of $10^{-4} \mathrm{eV}$ in the iterative solution of the electronic Hamiltonian. For the second step we used normal precision settings and an energy threshold of $10^{-5} \mathrm{eV}$.

The interface strength is estimated from the separation energy:

$\mathrm{E}_{\text {sep }}=\left(\mathrm{E}^{a-s l a b}+\mathrm{E}_{\mathrm{Zn}}^{\text {slab }}+\delta N_{\mathrm{Zn}} \mathrm{E}_{\mathrm{Zn}}^{b u l k}-\mathrm{E}_{\mathrm{Zn}_{\mid} \mid \mathrm{Zn}_{2} \mathrm{SiO}_{4}}\right) / S$

where $\mathrm{E}_{\mathrm{Zn}_{\mid} \mathrm{Zn}_{2} \mathrm{SiO}_{4}}, \mathrm{E}^{a-s l a b}$, and $\mathrm{E}_{\mathrm{Zn}}^{\text {slab }}$ are the total energies of the $\mathrm{Zn} / \mathrm{Zn}_{2} \mathrm{SiO}_{4}$ heterostructure, and of the isolated silicate and $\mathrm{Zn}$ slabs at the same in-plane lattice parameters. $\delta N_{\mathrm{Zn}}$ is the number of excess zinc atoms at the interface with respect to the desired $\mathrm{Zn}_{2} \mathrm{SiO}_{4}(001)$ termination and a Zn slab with atomically flat (0001) surface. These excess $\mathrm{Zn}$ atoms are assumed in equilibrium with zinc bulk $\left(\Delta \mu_{\mathrm{Zn}}=0\right)$. The interface stability is estimated from the interface energy:

$$
E_{i n t}=\sigma_{\mathrm{B}}+\sigma_{\mathrm{Zn}}-E_{\text {sep }}
$$

We have additionally checked that the separation and interface energies are only little modified by filling empty spaces at the interfaces by additional excess zinc atoms. For example, the largest increase of the interfacial strength is $0.05 \mathrm{~J} \mathrm{~m}^{-2}$ at the $\mathrm{Zn}$ interface.

For reference, simulations of the interface between $\mathrm{Zn}$ and the non-polar $\mathrm{ZnO}(10 \overline{10})$ surface termination were performed. For this interface a good matching is obtained with $(3 \times 1)$ $\mathrm{ZnO}(10 \overline{10})$ cell in coincidence with a $(2 \times 1)$ $\mathrm{Zn}(2 \overline{2} 01)$ one. The resulting interface mismatch along the two in-plane directions is equal to $8 \%$ and $-1 \%$, with an angle mismatch of $9 \%$. Also in this case, we fix the lattice parameters and angles to the average value between those of zinc and $\mathrm{ZnO}$.

Periodic slab replicas were systematically separated by at least $10 \AA$ of vacuum and we used dipole corrections to attenuate the effect of periodic boundary conditions in the direction normal to the slab surfaces. ${ }^{16,30}$ In all calculations, atomic positions were relaxed until forces become smaller than $0.01 \mathrm{eV} \AA^{-1}$.

\section{Results}

We start by a description of the structural and electronic characteristics of the most stable $\mathrm{Zn} / \mathrm{Zn}_{2} \mathrm{SiO}_{4}$ interfaces of different compositions. Thereafter, we report results on their thermodynamic stability under different oxygen environments and analyze the corresponding strengths of zinc-silicate interaction.

\subsection{Structural and electronic properties}

There are nine possible surface terminations which preserve the periodicity of the $(1 \times 1)$ $\mathrm{Zn}_{2} \mathrm{SiO}_{4}(001)$ surface. ${ }^{15}$ Since along the (001) direction, the repetitive unit cell is composed of the .../ $/ \mathrm{Zn}_{2} \mathrm{O}_{4} / \mathrm{Si} / \ldots$ sequence of atomic layers, the non-polar terminations are obtained when the number of oxygen atoms in the outermost layer exceeds by one the number of zinc atoms. The three terminations for which this condition is fulfilled are $\mathrm{Zn}_{2} \mathrm{O}_{3} / \mathrm{Si} / \ldots, \mathrm{ZnO}_{2} / \mathrm{Si} / \ldots$, and $\mathrm{O} / \mathrm{Si} / \ldots$ In order to label these surfaces in a way that defines their composition as well as their polarity (charge neutrality), we formally assign one oxygen atom from the sur- 


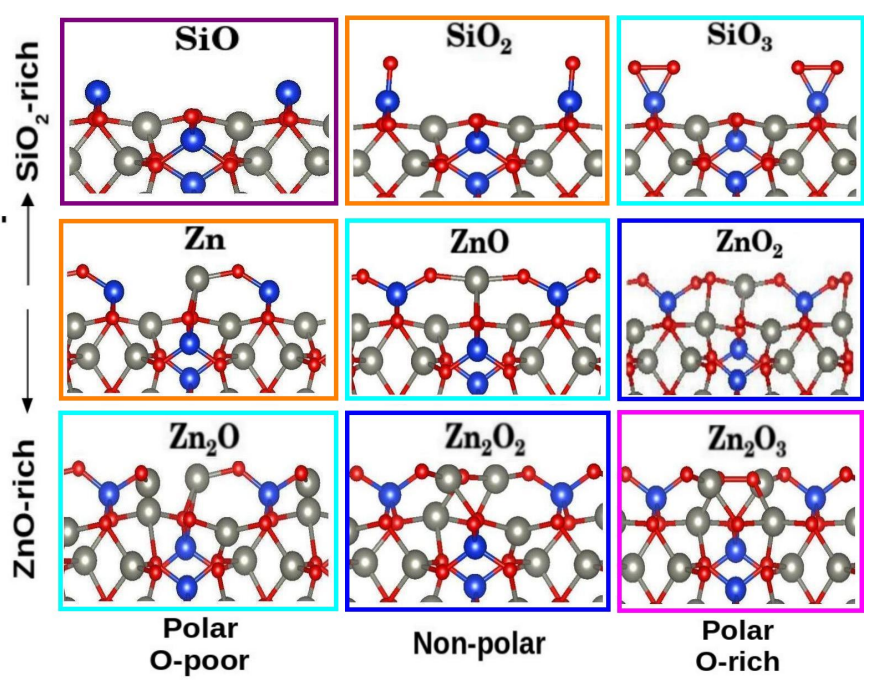

Figure 1: Atomic structures of the alternative $(1 \times 1)-\mathrm{Zn}_{2} \mathrm{SiO}_{4}(001)$ terminations. Si, Zn, and $\mathrm{O}$ atoms are represented by large blue, large grey, and medium red balls, respectively. Same frame colors indicate structures of equivalent stoichiometry when at interface with a zinc deposit. Adapted from Ref. 15.

face layer to the sub-surface Si atom. With this choice, the charge neutral (non-polar) terminations given above are labeled $\mathrm{Zn}_{2} \mathrm{O}_{2}, \mathrm{ZnO}$, and $\mathrm{SiO}_{2}$ (see Fig. 1). Only the $\mathrm{ZnO}$ termination is stoichiometric with respect to a dipole-free silicate bulk unit cell, and can be used to build a symmetric stoichiometric silicate slab. The $\mathrm{Zn}_{2} \mathrm{O}_{2}$ and $\mathrm{SiO}_{2}$ terminations are $\mathrm{ZnO}$-rich and $\mathrm{SiO}_{2}$-rich, respectively. Six polar terminations can be obtained by addition or subtraction of one oxygen atom to the three non-polar surfaces. Thus, the $\mathrm{SiO}_{3}, \mathrm{ZnO}_{2}$, and $\mathrm{Zn}_{2} \mathrm{O}_{3}$ are oxygen-rich terminations, and the $\mathrm{SiO}, \mathrm{Zn}$, and $\mathrm{Zn}_{2} \mathrm{O}$ are oxygen lean terminations, Fig. 1.

At the interface with metallic zinc, the terminations which differ by the number of zinc atoms only (e.g. the $\mathrm{ZnO}_{2}$ and $\mathrm{Zn}_{2} \mathrm{O}_{2}$ ones) result in identical interface stoichiometry. In absence of energy barriers, these terminations produce a unique optimal interface structure. The nine surface terminations therefore result in only five nonequivalent interfaces. Ordered from $\mathrm{ZnO}$-poor to $\mathrm{ZnO}$-rich, they are: $\mathrm{SiO}$, $\mathrm{Zn}\left(\mathrm{SiO}_{2}\right), \mathrm{Zn}_{2} \mathrm{O}\left(\mathrm{ZnO}, \mathrm{SiO}_{3}\right), \mathrm{Zn}_{2} \mathrm{O}_{2}\left(\mathrm{ZnO}_{2}\right)$ and $\mathrm{Zn}_{2} \mathrm{O}_{3}$, where different surface terminations which result in the same interface are indicated between the parentheses (and indicated by the same color of frames in Fig. 1).

The optimized structures of the five interfaces are presented in Fig. 2. Table 2 summarizes the number of interfacial $\mathrm{Zn}-\mathrm{O}$ bonds, the Bader charges of the silicate surface atoms, and the charge transfer to the zinc deposit, in comparison with atomic charges at the corresponding bare silicate surfaces. Several common features can be pointed out, which are independent of the stoichiometry and reflect general trends among the interfaces.

The under-coordinated oxygen atoms form one or two Zn-O bonds at the interface, associated with a partial ionization of the zinc atoms in the metal deposit. Due to the different surface density of such oxygen atoms, the number of bonds across the interface increases from two per cell at the O-poor interfaces $(\mathrm{SiO}, \mathrm{Zn}$ and $\left.\mathrm{Zn}_{2} \mathrm{O}\right)$ to three at the $\mathrm{Zn}_{2} \mathrm{O}_{2}$ interface, and to six at the O-rich $\mathrm{Zn}_{2} \mathrm{O}_{3}$ contact. The latter also displays the largest charge transfer, as the interaction with the metallic deposit breaks the $\mathrm{O}_{2}^{2-}$ group present at the bare surface. ${ }^{15}$ Conversely, O-poor interfaces (and particularly the $\mathrm{SiO}$ one) display a much weaker charge transfer, owing both to the smaller number of $\mathrm{Zn}$ $\mathrm{O}$ bonds across the interface and to the excess electrons already present at the silicate surface. The formation of Zn-O bonds systematically induces a strong rumpling in the interfacial layer of the zinc deposit, clearly visible in Fig. 2. We note that, in all cases, the second layer is much less affected.

At all interfaces, but at the $\mathrm{Zn}_{2} \mathrm{O}_{3}$ one, the oxidation of the metallic deposit is mainly compensated by a partial reduction of the interfacial zinc atoms belonging to the silicate. If, in general, this charge redistribution is mediated by the $\mathrm{Zn}-\mathrm{O}$ bonds, at zinc-rich interfaces ( $\mathrm{Zn}$ and $\mathrm{Zn}_{2} \mathrm{O}$ ) it is also due to a direct $\mathrm{Zn}-\mathrm{Zn}$ hybridization across the interface. Interestingly, negative excess charges located on silicon and zinc atoms at the $\mathrm{O}$-poor surfaces are never screened by the metallic deposit. Indeed, the low electronegativity of zinc prevents it from accepting additional electrons, as shown by similar values of Bader charges of silicon atoms at interfaces and at the corresponding bare silicate 


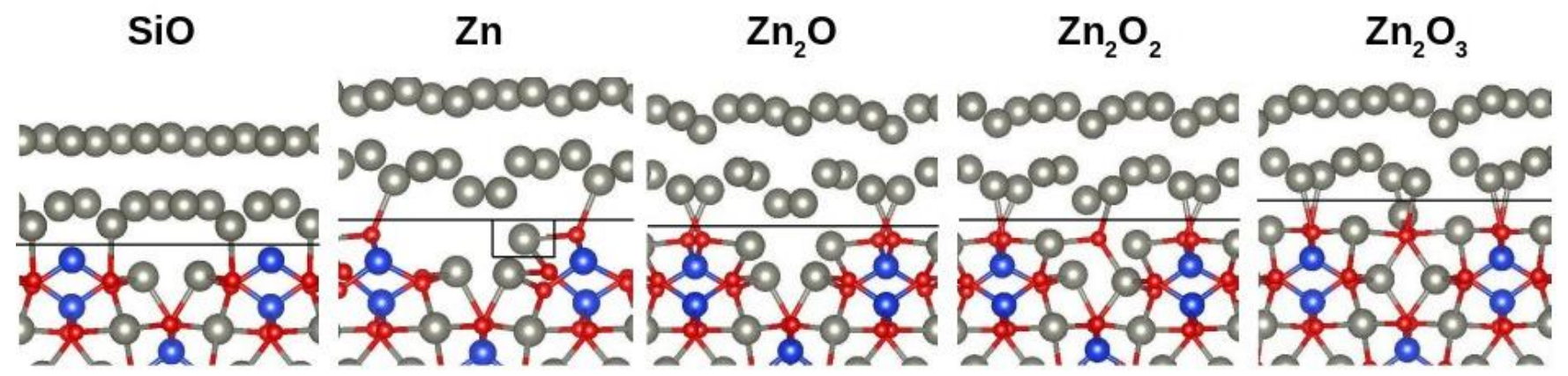

Figure 2: Atomic structures of the five nonequivalent $\mathrm{Zn} / \mathrm{Zn}_{2} \mathrm{SiO}_{4}(001)$ interfaces. Si, $\mathrm{Zn}$, and O atoms are represented by large blue, large grey, and medium red balls, respectively. Horizontal lines indicate the plane of the easiest separation for each interface. To better visualize the interfacial atomic structures, the silicate substrate was rotated by $90^{\circ}$ with respect to Fig. 1 .

surfaces.

\subsection{Interface energies}

Figure 3 (top) displays the interface energies of the $\mathrm{Zn} / \mathrm{Zn}_{2} \mathrm{SiO}_{4}(001)$ interfaces as a function of the oxygen chemical potential $\mu_{O}$. The relative stability of the various interfaces principally depends on two factors.

First, the ZnO-rich interfaces $\left(\mathrm{Zn}_{2} \mathrm{O}, \mathrm{Zn}_{2} \mathrm{O}_{2}\right.$ and $\mathrm{Zn}_{2} \mathrm{O}_{3}$ ) are systematically more stable than the $\mathrm{ZnO}$-poor ones ( $\mathrm{SiO}$ and $\mathrm{Zn}$ ). In the latter, strong Si-O bonds are broken upon interface formation and the resulting energy cost can only in small part be compensated by the creation of interfacial Zn-O bonds. Conversely, ZnO-rich interfaces involve no broken Si-O bonds. This energetic trend follows that reported for the corresponding bare silicate surfaces, shown in Fig. 3 (bottom). ${ }^{15}$ The second, less prominent factor is the number of $\mathrm{Zn}$ $\mathrm{O}$ bonds formed at the interface. The O-rich $\mathrm{Zn}_{2} \mathrm{O}_{3}$ interface, and to a lesser extent the nonpolar $\mathrm{Zn}_{2} \mathrm{O}_{2}$ one, are stabilized by a larger number of such interfacial bonds and a larger electron transfer from the metal deposit. This contrasts with the situation at bare surfaces, Fig. 3 (bottom), where the $\mathrm{Zn}_{2} \mathrm{O}_{3}$ is much less stable relatively to other terminations.

The three $\mathrm{ZnO}$-rich interfaces are stable at different values of the oxygen chemical potential, according to their different stoichiometry. We note that in oxygen-rich conditions, the interface energies of the $\mathrm{Zn} / \mathrm{Zn}_{2} \mathrm{O}_{3}$ and $\mathrm{Zn} / \mathrm{Zn}_{2} \mathrm{O}_{2}$ interfaces become negative. This reflects the thermodynamic preference for the oxidation of the entire zinc deposit under such oxygen conditions (zinc oxide is stable for $\Delta \mu_{O}>-3.19$ $\mathrm{eV})$. Interestingly, the $\mathrm{Zn} / \mathrm{Zn}_{2} \mathrm{O}$ interface has a remarkably similar stability to that of the reference $\mathrm{Zn} / \mathrm{ZnO}$ interface between zinc and zinc oxide (Fig. 3). This results from a compensation between opposite effects. The $\mathrm{Zn} / \mathrm{ZnO}$ contact displays three interfacial bonds per unit cell, as opposed to two at the $\mathrm{Zn} / \mathrm{Zn}_{2} \mathrm{O}$, but the area of its unit cell is slighly larger $(6.5 \%)$, and the Zn-O bonds are somewhat longer (2.02-2.08 $\AA$ ), thus suggesting a weaker interaction. Additionally, one should take into account that the $\mathrm{Zn}-\mathrm{O}$ bonds are more ionic in the bulk silicate than in the bulk zinc oxide ${ }^{15}$.

\subsection{Separation energies}

While several $\mathrm{Zn}_{2} \mathrm{SiO}_{4}(001)$ terminations can lead to the same interface stoichiometry and energy $\mathrm{E}_{\text {int }}$ when in contact with a zinc deposit $\left(\Delta \mu_{\mathrm{Zn}}=0\right)$, the separation energies $\mathrm{E}_{\text {sep }}$ are dependent on the precise plane of separation, and consequently on the precise composition of the silicate surface obtained after separation. The interface strength is then determined by its minimal value. Since $E_{\text {sep }}=\sigma_{\mathrm{B}}+\sigma_{\mathrm{Zn}}-E_{\text {int }}$ (Eq. 4) and only $\sigma_{\mathrm{B}}$ depends on the separation plane when $\Delta \mu_{\mathrm{Zn}}=0$, the minimal separation energy is obtained for the surface configuration with the lowest $\sigma_{\mathrm{B}}$, which corresponds to the most stable silicate termination exposed after 
Table 2: Number and lengths ( $)$ of zinc-oxygen bonds across the interface, Bader charges $Q(\mathbf{e})$ of interfacial silicate atoms, and total charge $\mathbf{Q}_{Z n, m e t}^{t o t}(\mathbf{e})$ of the metal deposit. The corresponding values in bulk silicate and at its bare surfaces are recalled for reference.

\begin{tabular}{lccccc|c} 
& $\mathrm{SiO}$ & $\mathrm{Zn}$ & $\mathrm{Zn}_{2} \mathrm{O}$ & $\mathrm{Zn}_{2} \mathrm{O}_{2}$ & $\mathrm{Zn}_{2} \mathrm{O}_{3}$ & $\mathrm{Bulk}$ \\
\hline $\mathrm{N}_{Z n-O}$ & 2 & 2 & 2 & 3 & 6 & - \\
$\mathrm{d}_{Z n-O}$ & 2.03 & $2.01 / 2.08$ & 1.99 & $1.92 / 2.01(\mathrm{x} 2)$ & $1.91(\mathrm{x} 2) / 2.05(\mathrm{x} 3) / 2.2$ & 1.99 \\
\hline $\mathrm{Q}_{O}$ & -1.39 & -1.45 & -1.41 & -1.15 & $-1.15(\mathrm{x} 2)$ & -1.43 \\
$\mathrm{Q}_{Z n}$ & $1.01(\mathrm{x} 2)$ & 0.59 & $0.7(\mathrm{x} 2) / 0.96(\mathrm{x} 2)$ & $0.7 / 1 / 1.13$ & 1.04 & 1.29 \\
$\mathrm{Q}_{S i}$ & 1.58 & 2.08 & 3.09 & 3.11 & 3.11 & 3.12 \\
$\mathrm{Q}_{Z n, m e t}^{\text {tot }}$ & 0.49 & 0.55 & 0.58 & 0.94 & 1.61 & - \\
\hline Bare surfaces & & & & & $-1.62(\mathrm{x} 2)$ & -1.43 \\
$\mathrm{Q}_{O}$ & -1.40 & $-1.31 /-1.38$ & -1.40 & -1.15 & 1.24 & 1.29 \\
$\mathrm{Q}_{Z n}$ & $1.24(\mathrm{x} 2)$ & 1.02 & $0.51 / 0.85$ & $1.23(\mathrm{x} 2)$ & 3.09 & 3.12 \\
$\mathrm{Q}_{S i}$ & 1.65 & 1.97 & 3.09 & 3.10 & &
\end{tabular}

Table 3: Separation energies $\mathrm{E}_{\text {sep }}\left(\mathrm{Jm}^{-2}\right)$ of the zinc/silicate interfaces respresented in Fig. 2.

\begin{tabular}{cccccc} 
& $\mathrm{SiO}$ & $\mathrm{Zn}$ & $\mathrm{Zn}_{2} \mathrm{O}$ & $\mathrm{Zn}_{2} \mathrm{O}_{2}$ & $\mathrm{Zn}_{2} \mathrm{O}_{3}$ \\
\hline $\mathrm{E}_{\text {sep }}$ & 0.96 & 0.92 & 1.16 & 1.31 & $1.93(1.17)$
\end{tabular}

the separation.

From the $\mathrm{Zn}_{2} \mathrm{SiO}_{4}(001)$ surface energies, Fig. 3 , one deduces that the preferential separation (the smallest $E_{\text {sep }}$ ) in the series of zinc/silicate interfaces should expose the $\mathrm{SiO}, \mathrm{SiO}_{2}$ (for the $\mathrm{Zn}$ interface), $\mathrm{Zn}_{2} \mathrm{O}, \mathrm{Zn}_{2} \mathrm{O}_{2}$, and $\mathrm{Zn}_{2} \mathrm{O}_{3}$ surfaces, respectively. The corresponding separation planes are explicitly plotted in Fig. 2. Systematically, they correspond to the most zincrich silicate terminations. The only exception is the $\mathrm{Zn}$ interface, which preferentially separates by exposing the $\mathrm{SiO}_{2}$ silicate termination.

The minimal separation energies of all zinc/silicate interfaces are reported in Table 3. We find that the interface strength increases with the number of $\mathrm{Zn}-\mathrm{O}$ bonds and with the amount of charge transferred $\mathrm{Q}_{Z n, m e t}^{\text {tot }}$, Tab. 2 . Separation energies are thus smaller for O-poor interfaces and progressively increase for the more O-rich ones. The largest value is obtained for the $\mathrm{Zn}_{2} \mathrm{O}_{3}$ interface, where the interaction with the zinc deposit provides the electrons necessary to heal the surface polarity. Conversely, at O-poor interfaces the zinc deposit is unable to accept additional electrons, leading to only a weaker interaction. Among the Opoor interfaces, the $\mathrm{Zn}_{2} \mathrm{O}$ one has a somewhat larger separation energy, due to shorter Zn-O bonds across the interface and to a somewhat larger degree of Zn-Zn hybridization.

In order to estimate the actual strength of the interfaces one has to additionally check if the interaction with the silicate substrate which induces a partial zinc oxidation does not reduce the cohesion within the zinc deposit. We have therefore reevaluated the separation energies of all the interfaces assuming that additional zinc atoms remain bound to the silicate surface after separation. We find that such alternative interface cleavage increases $\mathrm{E}_{\text {sep }}$ or leaves it unchanged, except for the oxygen-rich $\mathrm{Zn}_{2} \mathrm{O}_{3}$ interface. In this latter case, the additional zinc atom (per unit cell) bound to the silicate termination remains partially oxidized and compensates surface polarity more efficiently than the peroxo group present on the bare surface. The resulting significant reduction of the silicate surface energy is associated to a reduction of the interfacial strength by nearly $40 \%$, which brings the corresponding separation energy down to $1.17 \mathrm{~J} \mathrm{~m}^{-2}$.

Finally, we note that, as for the interface energies, the separation energies of ZnO-rich interfaces are very close to that of the reference $\mathrm{Zn} / \mathrm{ZnO}$ interface, $\mathrm{E}_{\text {sep }}=1.07 \mathrm{~J} \mathrm{~m}^{-2}$. As discussed above, this similarity is due to balance 

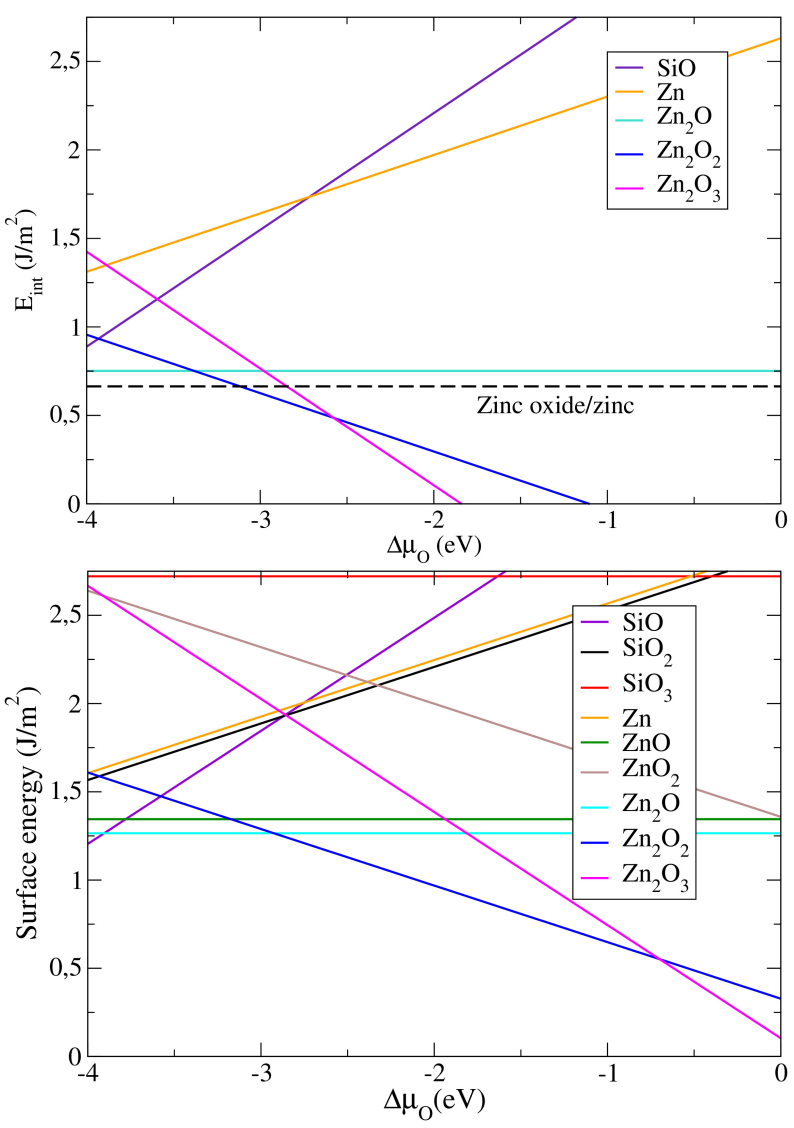

Figure 3: Top: calculated interface energies $\mathrm{E}_{\text {int }}$ $\left(\mathrm{J}^{-\mathrm{m}^{-2}}\right)$ of the $\mathrm{Zn} / \mathrm{Zn}_{2} \mathrm{SiO}_{4}(001)$ interfaces of a different stoichiometries as a function of oxygen chemical potential $\Delta \mu_{\mathrm{O}}$. As a reference, the dashed line represents the interface energy of the stoichiometric $\mathrm{Zn} / \mathrm{ZnO}(10 \overline{1} 0)$ interface. Bottom: the corresponding $\mathrm{Zn}_{2} \mathrm{SiO}_{4}(001)$ surface energies (in equilibrium with bulk zinc, $\left.\Delta \mu_{\mathrm{Zn}}=0\right)$.

between a larger number of $\mathrm{Zn}-\mathrm{O}$ bonds per unit cell at the $\mathrm{Zn} / \mathrm{ZnO}$ interface, and a larger bond strength and a smaller surface area at the zinc/silicate one.

\section{Discussion}

Based on the previous results, in the following we first highlight the favorable effect of an interfacial zinc silicate on the adhesion of zinc/silica contacts. Then, we explicitly test the validity of our predictions in the limit of ultra-thin interfacial silicate layers.

We recall that the zinc/silica interface is very weak, with a separation energy of $0.5 \mathrm{~J} \mathrm{~m}^{-2}$ or lower, due to the reconstruction of the silicate surface and the formation of weakly interacting siloxane rings. ${ }^{10}$ If compared to the calculated separation energy in bulk zinc $\left(1.05 \mathrm{~J} \mathrm{~m}^{-2}\right)$, this clearly shows that the poor performance of zinc coatings to the silica-covered steels is due to the interfacial cleavage at the weaklyinteracting metal/oxide interface. Our present computational results show that zinc/silicate interfaces systematically show much better adhesion characteristics, with $\mathrm{E}_{\text {sep }}$ twice or more larger compared to the zinc/silica one (see Tab. $3)$.

On the one hand, the adhesion energies at all ZnO-rich interfaces $\left(\mathrm{Zn}_{2} \mathrm{O}, \mathrm{Zn}_{2} \mathrm{O}_{2}\right.$ and $\left.\mathrm{Zn}_{2} \mathrm{O}_{3}\right)$ are remarkably similar, ranging from 1.15 to $1.30 \mathrm{~J} \mathrm{~m}^{-2}$, after having taken into account the decohesion of the zinc deposit at the $\mathrm{Zn}_{2} \mathrm{O}_{3}$ interface. They are considerably larger than the zinc/silica one and, within the precision of our estimation, stronger than that in bulk zinc. They are therefore sufficient to transform the interfacial cleavage of the zinc/silica interface into a cohesive one within zinc at the zinc/silicate contact. Such adhesion improvement is due to the presence of unsaturated oxygen atoms at silicate surfaces which enables a continuation of the Zn-O bond network upon zinc deposition. Most importantly, these ZnOrich interfaces are also thermodynamically favored under any oxygen condition and are thus the most likely to form independently of the reaction pathway.

On the other hand, at $\mathrm{SiO}_{2}$-rich silicate terminations, the low surface density of Si-O groups prevents the formation of siloxane rings, which results in strong interfacial Zn-O bonds, similar to those formed at the zinc/silica interfaces upon (activated) siloxane depolymarization. ${ }^{10,11}$ However, the twice lower density of such bonds at the zinc/silicate interface, makes its separation energy $\left(\mathrm{E}_{\text {sep }} \sim 1.0 \mathrm{~J} \mathrm{~m}^{-2}\right)$ roughly twice smaller compared to the corresponding non-reconstructed zinc/silica interface $\left(\mathrm{E}_{\text {sep }} \geq 1.8 \mathrm{~J} \mathrm{~m}^{-2}\right.$, Ref. $\left.{ }^{10}\right)$, and thus somewhat smaller than the breaking energy within bulk zinc. However, we remind that the $\mathrm{SiO}_{2}$ rich silicate surfaces and the associated interfaces with zinc are thermodynamically less sta- 


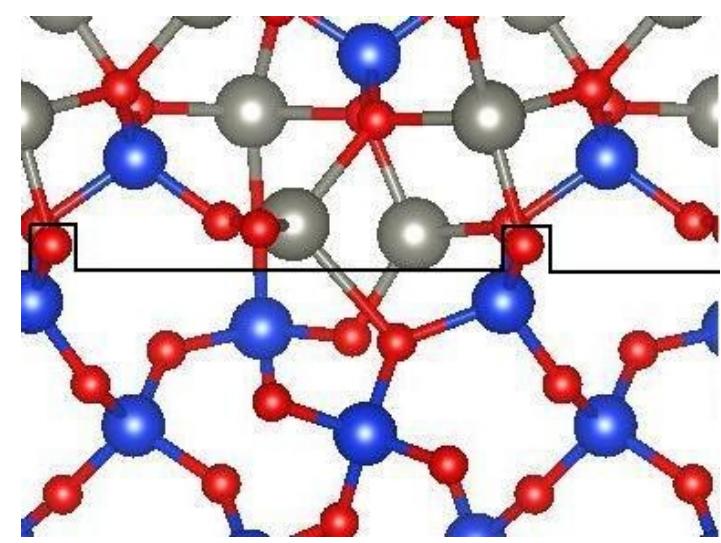

Figure 4: Optimized atomic structure of a $\mathrm{Zn}_{2} \mathrm{SiO}_{4}(001) / \mathrm{SiO}_{2}$ interface. Si, $\mathrm{Zn}$, and $\mathrm{O}$ atoms are represented by large blue, large grey, and medium red balls, respectively. The black line indicates the separation plane.

ble than the ZnO-rich ones and are not expected to spontaneously form under any oxygen conditions.

It is also worthwhile to compare zinc adhesion at silicate surfaces with that at oxygen-rich silica surfaces which can be obtained by silica pre-hydroxylation followed by interface dehydrogenation ${ }^{10,11}$. In this latter case, a larger density of Zn-O bonds is formed than at the silicate/zinc interfaces $\left(24.8\right.$ bonds $/ \mathrm{nm}^{2}$, to be compared with 6.2 at the $\mathrm{Zn}_{2} \mathrm{O}_{2}$ silicate/zinc interface), which translates in a very strong interfacial adhesion. Unfortunately, the excess oxygen partially oxidizes the interfacial zinc atoms, leading to a significant decohesion of the metal deposit. In contrast, for silicate/zinc interfaces a moderately strong adhesion is obtained with stoichiometric terminations, resulting in only negligible decohesion effects.

While our results show that the presence of silicate produces a substantial improvement of adhesion at the metal/oxide interface, the overall performance of the zinc/silicate/silica heterostructure also depends on the strength of the $\mathrm{Zn}_{2} \mathrm{SiO}_{4} / \mathrm{SiO}_{2}$ contact. As to asses its performance, we have estimated the separation energy of the stoichiometric $\mathrm{SiO}_{2}$ termination of silica ${ }^{10}$ from the non-polar $\mathrm{Zn}_{2} \mathrm{O}_{2}$ termination of the silicate (shown in Fig. 4) which, due to the high density of interfacial Zn-O bonds and the overall charge neutrality is expected to be among the most stable silicate/silica contacts. We find a large separation energy of $2.61 \mathrm{~J} \mathrm{~m}^{-2}$, consistently with the previous findings that oxide/oxide interfaces are considerebly stronger than the non-reactive metal/oxide ones. ${ }^{31} \mathrm{We}$ note that even though this separation energy is reduced to about $1.3 \mathrm{~J} \mathrm{~m}^{-2}$ by the reconstruction of the exposed silica surface, the separation process nevertheless requires the breaking of interfacial bonds in the first step.

Since the above predictions are based on results obtained for interfaces between massive materials, we have further tested if a similar adhesion improvement is also obtained with an ultra-thin interfacial silicate film, which may be more relevant in a realistic situation. To this goal we have explicitly simulated the $\mathrm{Zn} / \mathrm{Zn}_{2} \mathrm{SiO}_{4} / \mathrm{SiO}_{2}$ heterostructure, with only five-layer-thick, $\mathrm{Zn}_{2} \mathrm{O}_{2}$-terminated silicate film, Fig. 5. We find that despite a noticeable reduction of the adhesion energies at both zinc/silicate and silicate/silica interfaces (1.15 and $2.06 \mathrm{~J} \mathrm{~m}^{-2}$, respectively), the adhesion remains substantially improved with respect to that at the zinc/silica interface $\left(E_{\text {sep }} \sim 0.5 \mathrm{~J}\right.$ $\left.\mathrm{m}^{-2}\right)$. The cleavage plane remains localized in bulk zinc $\left(E_{\text {sep }}=1.05 \mathrm{~J} \mathrm{~m}^{-2}\right)$, thus confirming the suppression of the weak metal/oxide contact by the formation of an interfacial silicate, even in the limit of an ultra-thin film.

Turning now to the conditions required for the formation of such an interfacial silicate buffer, we remind that zinc silicate is thermodynamically more stable than zinc oxide and silica separately (negative formation energy of $\left.-0.2 \mathrm{eV},{ }^{15}\right)$. Its formation is thus expected already under oxygen conditions somewhat more oxygen-poor than those necessary for zinc oxidation $\left(\Delta \mu_{O}>-3.2 \mathrm{eV}^{15}\right)$. However, in practical realizations, kinetics may play an important role and impede a spontaneous silicate formation. As to facilitate interface oxidation, the required oxygen excess at the zinc/silica contact could be provided by some pre-hydroxylation of the silica surface. ${ }^{11}$ If followed by zinc deposition at high temperature, the mixing of the two oxides may be efficiently promoted, leading to the formation of an ultra-thin interfacial silicate film. However, we note that at realistic 


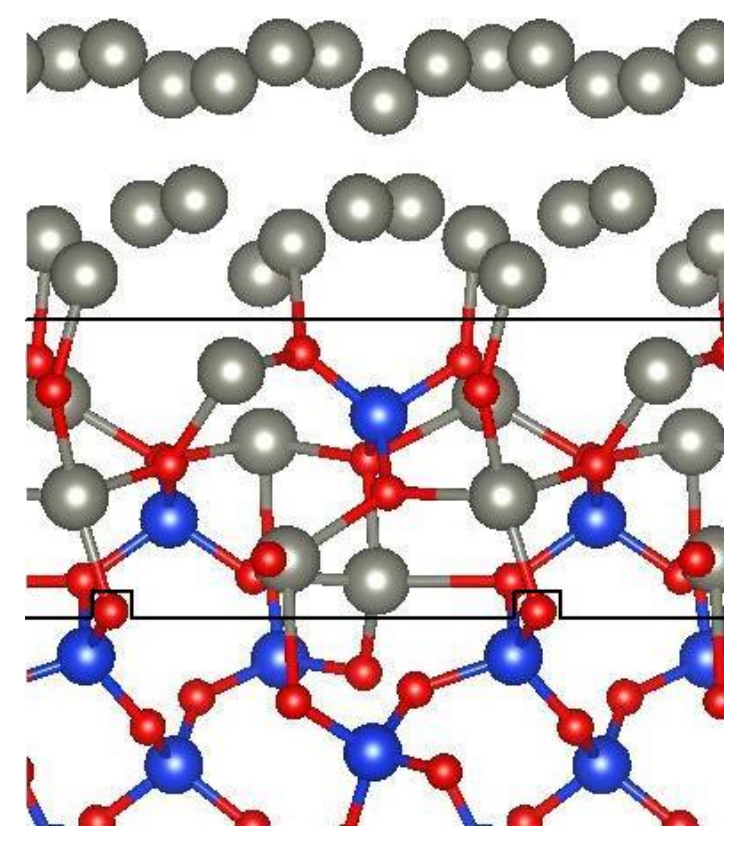

Figure 5: Optimized atomic structure of a $\mathrm{Zn} / \mathrm{Zn}_{2} \mathrm{SiO}_{4} / \mathrm{SiO}_{2}$ heterostructure representing an ultra-thin silicate film at the zinc/silica interface. $\mathrm{Si}, \mathrm{Zn}$, and $\mathrm{O}$ atoms are represented by large blue, large grey, and medium red balls, respectively. Black lines indicate the separation planes at the two interfaces.

hydroxyl group densities, the amount of oxygen could be insufficient. Alternatively, a thin buffer layer of $\mathrm{ZnO}$ or $\mathrm{Zn}_{2} \mathrm{SiO}_{4}$ could be directly deposited on the silica surface before the application of the zinc coating, thus resulting in a thicker silicate layer at the interface.

\section{Conclusions}

In summary, relying on DFT calculations, we have investigated the structural and energetic characteristics of $\mathrm{Zn} / \mathrm{Zn}_{2} \mathrm{SiO}_{4}$ interfaces, in order to assess the impact of an interfacial silicate on the adhesion at a zinc/silica interface. We have considered all possible interface stoichimetries in the $(1 \times 1)$ zinc/silicate unit cell, involving all oxygen-poor, stoichiometric ( $\mathrm{ZnO}$ and $\mathrm{SiO}_{2}$-rich), and O-rich terminations of the silicate surface.

We find that strong Zn-O bonds form at all these interfaces, leading to adhesion energies which are systematically twice or more larger compared to those at the weakly-interacting zinc/silica interfaces. Moreover, the density of these bonds is particularly large at the $\mathrm{Zn} / \mathrm{Zn}$ $\mathrm{O}$ rich silicate interfaces, so that their adhesion energy exceeds the separation energy within bulk zinc. This turns the interfacial cleavage at the zinc/silica interface into a cohesive one in presence of the interfacial silicate. Interestingly, the ZnO-rich interfaces are found to be also the most thermodynamically stable under all considered oxygen conditions, since their formation does not involve breaking of any strong Si-O bond. Moreover, we explicitly demonstrate that these predictions, based on results obtained for interfaces between massive materials, also hold in the limit of an ultra-thin interfacial silicate film, likely more relevant in practical applications.

Since mixing of silica and zinc oxide is thermodynamically favored, promoting the formation of an interfacial silicate is therefore a promising pathway towards shifting the cleavage from the weakly-interacting zinc/silica contact into the zinc deposit. This substantial improvement of interface strength opens an interesting practical possibility to optimize the adhesion of anticorrosive zinc coatings of Sirich steel grades, of crucial importance in steelmaking and automotive industries.

Acknowledgement J. Baima acknowledges a post-doctoral grant from ArcelorMittal Maizières Research.

\section{References}

(1) Marder, A. R. The Metallurgy of ZincCoated Steel. Prog. Mater. Sci. 2000, 45, 191-271.

(2) Drillet, P.; Zermout, Z.; Bouleau, D.; Mataigne, J.-M.; Claessens, S. Selective Oxidation of High $\mathrm{Si}, \mathrm{Mn}$ and Al Steel Grades During Recrystallization Annealing and Steel/Zn Reactivity. Rev. Metall.Cah. Inf. Tech. 2004, 10, 831-837.

(3) Jiang, H.-T.; Ding, W.; Tang, D.; Huang, W. Mechanical Property and Microstructural Characterization of C-Mn- 
Al-Si Hot Dip Galvanizing TRIP Steel. J. Iron Steel Res. 2012, 19, 29-36.

(4) Wang, W.; Li, M.; He, C.; Wei, X.; Wang, D.; Dub, H. Experimental Study on High Strain Rate Behavior of High Strength 600-1000 MPa Dual Phase Steels and $1200 \mathrm{MPa}$ Fully Martensitic Steels. Mater. Des. 2013, 47, 510-521.

(5) Mertens, A.; Bellhouse, E. M.; McDermid, J. R. Microstructure and Mechanical Properties of a Mixed Si-Al TRIPAssisted Steel Subjected to Continuous Galvanizing Heat Treatments. Mater. Sci. Eng. A 2014, 608, 249-257.

(6) Fonstein, N., Ed. Advanced high strength sheet steels, 1st ed.; Springer Int. Publishing: Switzerland, 2015.

(7) Hu, B.; Luo, H.; Yang, F.; Dong, H. Recent Progress in Medium-Mn Steels Made with New Designing Strategies, a Review. J. Mater. Sci. Technol. 2017, 33, 14571464.

(8) Emo, J.; Maugis, P.; Perlade, A. Austenite Growth and Stability in Medium Mn, Medium Al Fe-C-Mn-Al Steels. Comput. Mater. Sci. 2016, 125, 206-217.

(9) Tonizzo, Q.; Gourgues-Lorenzon, A.-F.; Maziére, M.; Perlade, A.; Zuazo, I. Microstructure, Plastic Flow and Fracture Behavior of Ferrite-austenite Duplex Low Density Medium Mn Steel. Mater. Sci. Eng. A 2017, 706, 217-226.

(10) Le, H.-L. T.; Goniakowski, J.; Noguera, C.; Koltsov, A.; Mataigne, J.M. Structural, electronic and adhesion characteristics of zinc/silica interfaces: $a b$ initio study on zinc/ $\beta$-cristobalite. Phys. Chem. Chem. Phys. 2018, 20, 6254-6263.

(11) Le, H.-L. T.; Goniakowski, J.; Noguera, C.; Koltsov, A.; Mataigne, J.-M. Effects of surface hydroxylation on adhesion at zinc/silica interfaces. Phys. Chem. Chem. Phys. 2018, 20, 15581-15588.
(12) Xu, X.; Wang, P.; Qi, Z.; Ming, H.; Xu, J.; Liu, H.; Shi, C.; Lu, G.; Ge, W. Formation mechanism of Zn2SiO4 crystal and amorphous $\mathrm{SiO} 2$ in $\mathrm{ZnO} / \mathrm{Si}$ system. J. Phys.: Cond. Mat. 2003, 15, L607.

(13) He, H.; Wang, Y.; Zou, Y. Photoluminescence property of $\mathrm{ZnO}-\mathrm{SiO} 2$ composites synthesized by sol-gel method. J. Phys. D: Appl. Phys. 2003, 36, 2972.

(14) Karazhanov, S. Z.; Ravindran, P.; Vajeeston, P.; Ulyashin, A. G.; Fjellvåg, H.; Svensson, B. G. Phase stability and pressure-induced structural transitions at zero temperature in $\mathrm{ZnSiO} 3$ and $\mathrm{Zn} 2 \mathrm{SiO}$ 4. J. Phys.: Cond. Mat. 2009, 21, 485801.

(15) Baima, J.; Goniakowski, J.; Noguera, C.; Koltsov, A.; Mataigne, J.-M. Surface thermodynamics of silicate compounds: the case of Zn2SiO4(001) surfaces and thin films. Phys. Chem. Chem. Phys. 2019, 21, 13287-13295.

(16) Kresse, G.; Furthmuller, J. Efficient Iterative Schemes for ab initio Total Energy Calculations Using a Plane-Wave Basis Set. Phys. Rev. B 1996, 54, 11169 11186.

(17) Kresse, G.; Hafner, J. Ab initio Molecular Dynamics for Liquid Metals. Phys. Rev. B 1993, 47, 558-561.

(18) Dion, M.; Rydberg, H.; Schroder, E.; Langreth, D. C.; Lundqvist, B. I. Van der Waals Density Functional for General Geometries. Phys. Rev. Lett. 2004, 92, 246401.

(19) Klimes, J.; Bowler, D. R.; Michaelides, A. Chemical Accuracy for the van der Waals Density Functional. J. Phys.: Cond. Matt. 2010, 22, 022201.

(20) Klimes, J.; Bowler, D. R.; Michaelides, A. Van der Waals Density Functionals Applied to Solids. Phys. Rev. B 2011, 83, 195131. 
(21) Blöchl, P. E. Projector Augmented-Wave Method. Phys. Rev. B 1994, 50, 1795317979 .

(22) Kresse, G.; Joubert, J. From Ultrasoft Pseudopotentials to the Projector Augmented-Wave Method. Phys. Rev. B 1999, 59, 1758-1775.

(23) Bader, R. F. W. A Quantum Theory of Molecular Structure and its Applications. Chem. Rev. 1991, 91, 893-928.

(24) Henkelman, G.; Arnaldsson, A.; Jonsson, H. A Fast and Robust Algorithm for Bader Decomposition of Charge Density. Comput. Mater. Sci. 2006, 36, 354-360.

(25) Momma, K.; Izumi, F. VESTA 3 for threedimensional visualization of crystal, volumetric and morphology data. J. Appl. Crystallogr. 2011, 41, 1272-1276.

(26) Perdew, J. P.; Chevary, J. A.; Vosko, S. H.; Jackson, K. A.; Pederson, M. R.; Singh, D. J.; Fiolhais, C. Atoms, molecules, solids, and surfaces: Applications of the generalized gradient approximation for exchange and correlation. Phys. Rev. B 1992, 46, 6671-6687.

(27) Chase, M. W., Jr., Ed. NIST-JANAF Themochemical Tables, Fourth Edition; J. Phys. Chem. Ref. Data, Monograph 9; 1998.

(28) Syono, Y.; Akimoto, S.-I.; Matsui, Y. High pressure transformations in zinc silicates. J. Solid State Chem. 1971, 3, 369-380.

(29) Marumo, F.; Syono, Y. The crystal structure of $\mathrm{Zn}_{2} \mathrm{SiO}_{4}$-II, a high-pressure phase of willemite. Acta Crystallogr. B 1971, 27, $1868-1870$.

(30) Neugebauer, J.; Scheffler, M. Adsorbatesubstrate and Adsorbate-adsorbate Interactions of $\mathrm{Na}$ and $\mathrm{K}$ Adlayers on $\mathrm{Al}(111)$. Phys. Rev. B 1992, 46, 16067-16080.

(31) Le, H.-L. T.; Goniakowski, J.; Noguera, C.; Koltsov, A.; Mataigne, J.-M.
Improving Adhesion at the Alumina/Zinc Interface by Stainless Steel Buffers. $J$. Phys. Chem. C 2017, 121, 25143-25151.

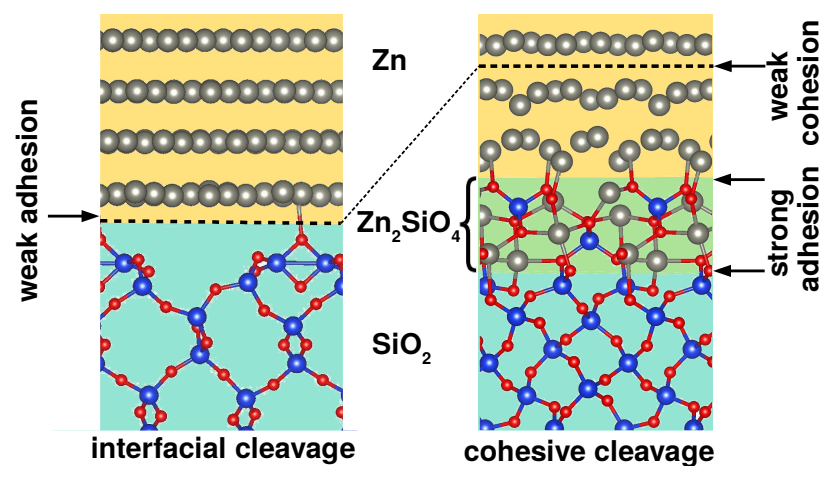

